\title{
PERTUMBUHAN DAN PRODUKSI TANAMAN TOMAT (Licoprsicon esculentum Mill)PADA BERBAGAI JARAK TANAM DAN PEMANGKASAN
}

\author{
(Growth and Production of Tomato (Licoprsicon esculentum Mill) \\ on Prunning and Distance of plant)
}

\author{
St Sabahannur ${ }^{1}$ dan Lingga Herawati ${ }^{2}$ \\ ${ }^{1)}$ Fakultas Pertanian Universitas Muslim Indonesia, Makassar \\ Email:siti_sabahan@yahoo.com
}

\begin{abstract}
The airs of the study was to determine the effect of plant spacing and pruning on the growth and production of tomato plants. The research was conducted in the form of Randomized Block Design consisting of 2 Factorials. The first factor is plant spacing consisting of three levels: $70 \mathrm{~cm} \times 50 \mathrm{~cm}, 60 \mathrm{~cm}$ $x 50 \mathrm{~cm}$ and $40 \mathrm{~cm} \times 50 \mathrm{~cm}$. The second factor of pruning consists of 3 levels: not trimmed (control), trimmed and leaving two branches and trimmed and leaving three branches. The parameters observed were: number of leaves, flowering age, fruit crop weight and production per hectare. The results showed that plant spacing and pruning significantly affected the weight of fruit per plant, and production per hectare, but no significant effect on the number of leaves, and the age of flowering, and the interaction only had significant effect on flowering age. Spacing of $40 \mathrm{~cm} \times 50 \mathrm{~cm}$ produces a higher production of 22.83 tons per hectare. Treatment of pruning by leaving three main branches produces the best crop production of 23.31 tons per hectare. Planting distance of $60 \mathrm{~cm} \times 50 \mathrm{~cm}$ and pruning which leaves three branches produces flowering age of 19.67 days.
\end{abstract}

Keywords : Prunning, Plant Spacing, Production, Tomato, Growth

\section{PENDAHULUAN}

Tomat (Lycopersicon esculentum Miller) merupakan salah satu komoditas hortikultura yang memiliki nilai ekonomi penting di Indonesia. Tomat adalah salah satu jenis sayuran buah yang mempunyai prospek yang baik dalam pengembangan agribisnis, karena nilai ekonominya tinggi, gizi yang dikandung seperti protein, karbohidrat, lemak, mineral dan vitamin (Bernadus \& Wahyu, 2002).

Tomat dapat meningkatkan pendapatan dibandingkan komoditas sayuran lainnya. Pollage melaporkan hasil analisa usahatani yang dilakukan di Sulawesi Selatan pada tahun 1990, dari lima komoditas sayuran utama yang diusahakan, tomat menduduki urutan kedua dalam dalam hal besarnya pendapatan bersih. Tercatat bahwa pendapatan bersih yang diperoleh dari usaha tani kubis, tomat, kentang, dan bawang merah berturut-turut 1,$93 ; 1,75$; 1,$58 ; 1,10$ dan 0,90 juta rupiah permusim tanam (Duriat, 1997).

Terdapat beberapa kendala yang dihadapi dalam pengusahaan penanaman tomat dataran rendah, diantaranya suhu 

berbagai Jarak Tanam dan Pemangkasan.

yangtinggi, kesuburan tanah yang rendah, tingkat kemasaman tanah yang tinggi, dan serangan hama penyakit. Agar pemanfaatan lahan dataran rendah optimal, perlu adanya perbaikan budidaya, seperti pengaturan jarak tanam dan pemangkasan.

Mengatur jarak tanam berarti memberi ruang lingkup hidup yang sama/merata bagi setiap tanaman. Dengan mengatur jarak tanam akan diperoleh barisan-barisan tanaman yang teratur sehingga mudah dalam melakukan pengelolaan tanaman. Jarak tanam yang tidak teratur, akan mengakibatkan kerugian bagi pertumbuhan maupun bagi produksi buah tomat itu sendiri. Untuk penanaman tanaman tomat, dibutuhkan jarak tanam yang ideal sehingga pertumbuhan dan perkembangan dapat terjadi secara optimal, serta dapat menghasilkan produksi buah yang tinggi. Jarak tanam untuk tanaman tomat yang ideal adalah $40 \mathrm{~cm} \times 50 \mathrm{~cm}$, sedangkan menurut Wiryanta (2002) penanaman bibit tomat pada bedengan dengan jarak tanam $70 \mathrm{~cm} \times 50 \mathrm{~cm}$. Jarak tanam adalah jarak yang sesuai dengan perkembangan bagian atas tanaman serta cukup tersedianya ruang bagi perkembangan perakaran di dalam tanah, dengan demikian pilihan jarak tanam erat kaitannya dengan sifat pertumbuhan, sumber bahan makanan dan kesuburan tanah (Nuraini, 1993).

Faktor lain yang berpengaruh terhadap produksi adalah pemangkasan. Pada budidaya tanaman tomat dengan sistem pemangkasan dilakukan terhadap tunas-tunas muda dan pucuk batang. Pemangkasan ini dimaksud untuk menjaga tanaman tomat waktu berbuah (Primantoro, 2004). Pemangkasan pada tanaman tomat di Indonesia jarang dilakukan hal ini disebabkan karena kurangnya pengetahuan tentang teknik dan cara pemangkasan, serta pertimbangan tenaga kerja (Fitriani, 2012).

Pemangkasan dimaksudkan agar dapat diperoleh buah yang besar dan cepat masak. Pemangkasan cabang utama bertujuan untuk mengurangi jumlah cabang utama, dimana diharapkan fotosintat yang dihasilkan dapat lebih maksimal untuk pembentukan dan perkembangan buah tomat. Pemangkasan dilakukan sekali atau dua kali sebulan yaitu dengan cara memangkas bagian pucuk atau cabang ketiga pada batang pokok, atau cabang kelima pada kedua cabang yang dibiarkan hidup. Pemangkasan tanaman tomat dapat dilakukan dengan dua cara yaitu pemangkasan tunas muda 

berbagai Jarak Tanam dan Pemangkasan.

dan pemangkasan batang (Anonim, 2010).

Berdasarkan uraian tersebut, maka

dilakukan penelitian untuk mengetahui

pengaruh jarak tanam dan pemangkasan

terhadap pertumbuhan dan produksi tanaman tomat.

\section{METODE PENELITIAN}

\section{Tempat dan Waktu}

Penelitian dilaksanakan di Desa Madani, Kecamatan Wotu Kabupaten Luwu Timur Sulawasi Selatan. Penelitian berlangsung bulan April sampai Juli 2016

\section{Bahan dan Alat}

Bahan yang digunakan dalam penelitian meliputi: benih tomat varietas Permata F1, Pupuk kandang sapi, polybag, pupuk NPK Mutiara, dan alat alat yang digunakan: cangkul, sekop, sabit, ember, keranjang, gunting, Handsprayer, paranet, jangka sorong, bambu untuk ajir/lanjaran, handsprayer dan timbangan.

\section{Rancangan Penelitian}

Penelitian dibuat dalam bentuk Rancangan Acak Kelompok (RAK) pola faktorial dua faktor.Faktor pertama jarak tanam yang terdiri dari 3 taraf yaitu: $70 \mathrm{~cm} \times 50 \mathrm{~cm}$
$(\mathrm{J} 1), 60 \mathrm{~cm} \times 50 \mathrm{~cm}(\mathrm{~J} 2), 40 \mathrm{~cm} \times 50 \mathrm{~cm}$ (J3). Faktor kedua adalah pemangkasan yang terdiri dari 3 taraf yaitu: Tidak dipangkas (P0), dipangkas dengan menyisakan dua cabang primer (P1), dipangkas dengan menyisakan tiga cabang primer $(\mathrm{P} 2)$. Dari kedua faktor tersebut diperoleh 9 kombinasi perlakuan yang diulang sebanyak tiga kali sehingga terdapat 27 unit percobaan.

\section{Metode pelaksanaan \\ Pemangkasan.}

Pemangkasan dilakukan setiap 2 minggu sekali, dengan cara memotong tunas-tunas yang muncul pada ketiak daun dan menyisakan dua dan tiga cabang primer (sesuai perlakuan), dan apabila terdapat tunas-tunas baru yang tumbuh pada batang utama selain cabang yang dipelihara maka segera dilakukan pemangkasan.

\section{Parameter Pengamatan}

Untuk melihat pengaruh jarak tanam dan pemangkasan terhadap tanaman tomat maka dilakukan pengamatan terhadap komponen pertumbuhan dan produksi sebagai berikut:jumlah daun, umur berbunga $50 \%$ (hari) diamati sejak 


berbagai Jarak Tanam dan Pemangkasan.

penanaman sampai $50 \%$ tanaman sidik ragamnya menunjukkan bahwa berbunga, bobot buah per tanaman $(\mathrm{kg})$ perlakuan jarak tanam dan pemangkasan dan produksi per hektar (ton/ha) serta interaksinya tidak berpengaruh nyata terhadap jumlah daun. Rata-rata jumlah

\section{HASIL DAN PEMBAHASAN daun dapat dilihat pada Gambar 1.}

\section{Jumlah Daun}

Data hasil pengamatan jumlah daun tanama tomat pada umur 4 MST dan

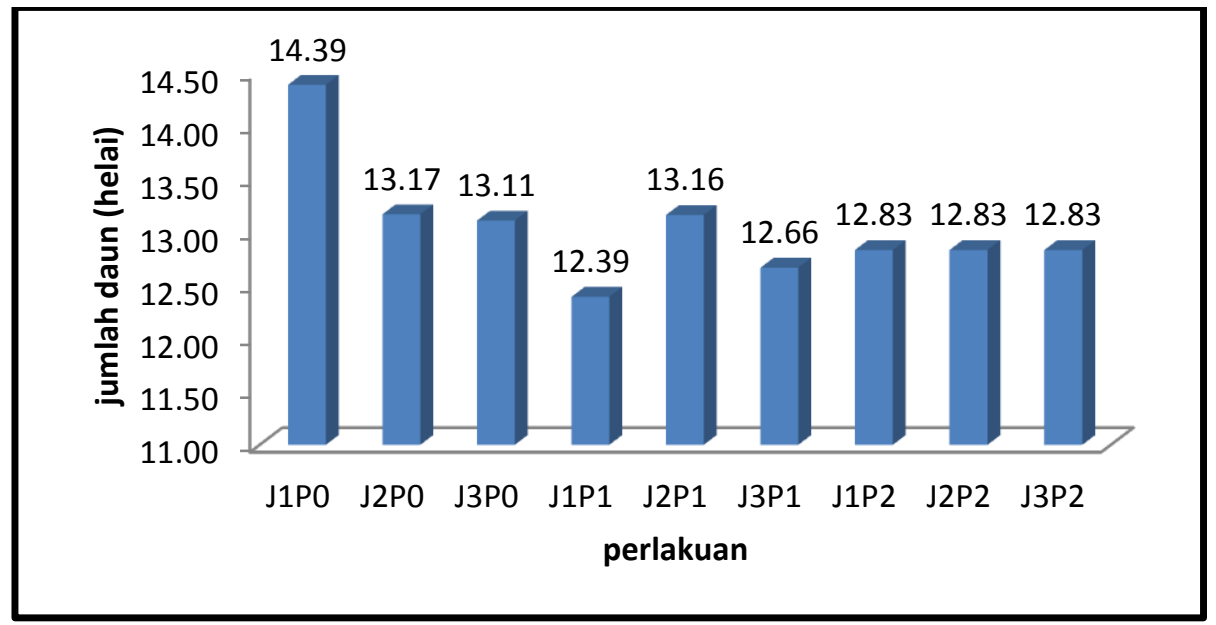

Gambar 1. Rata-rata Jumlah Daun Tanaman Tomat Umur 4 MST

Gambar 1 menunjukkan jumlah daun tanaman tomat pada umur 4 MST dengan jarak tanam $60 \mathrm{~cm} \quad \mathrm{x} 50 \mathrm{~cm}$ dan pemangkasan menyisakan 2 cabang (J2P1) menghasilkan jumlah daun terbanyak yaitu 14,39 helai, sedangkan jumlah daun terendah terdapat pada perlakuan jarak tanam $70 \mathrm{~cm}$ x $50 \mathrm{~cm}$ dan pemangkasan yang menyisakan 2 cabang (J1P1) yaitu menghasilkan 12,39 helai.

\section{Umur Berbunga}

Data hasil pengamatan umur berbunga dan sidik ragamnya menunjukkan bahwa perlakuan jarak tanam dan pemangkasan berpengaruh tidak nyata, namun interaksinya berpengaruh nyata terhadap umur berbunga tanaman tomat. Hasil uji lanjut disajikan pada Tabel 1 

Tabel 1. Rata-rata Umur Berbunga Tanaman Tomat (Hari)

\begin{tabular}{clc}
\hline Perlakuan & \multicolumn{1}{c}{$\begin{array}{c}\text { Umur } \\
\text { berbunga }\end{array}$} & NP BNT 0,05 \\
\hline J1P0 & $22,33^{\mathrm{b}}$ & \\
J2P0 & $23,00^{\mathrm{b}}$ & \\
J3P0 & $21,67^{\mathrm{ab}}$ & \\
J1P1 & $20,33^{\mathrm{ab}}$ & 2,37 \\
J2P1 & $27,00^{\mathrm{c}}$ & \\
J3P1 & $21,67^{\mathrm{ab}}$ & \\
J1P2 & $23,33^{\mathrm{b}}$ & \\
J2P2 & $19,67^{\mathrm{a}}$ & \\
J3P2 & $20,33^{\mathrm{ab}}$ & \\
\hline
\end{tabular}

Keterangan: Angka yang diikuti oleh huruf yang berbeda berartiberbeda nyata pada taraf uji BNT 0,05 .

Tabel 1 menunjukkan umur Bobot Buah/tanaman

berbunga yang tercepat terdapat pada Data hasil pengamatan bobot jarak tanam $60 \mathrm{~cm} \times 50 \mathrm{~cm}$ dan buah/tanaman sebanyak tiga kali panen pemangkasan menyisakan tiga cabang dan sidik ragamnya menunjukkan bahwa (J2P2) yaitu 19,67 hari dan tidak berbeda perlakuan jarak tanam dan pemangkasan nyata dengan perlakuan J3P0, J1P1, J3P1 berpengaruh sangat nyata, namun dan J3P2 namun berbeda nyata dengan interaksinya tidak berpengaruh nyata perlakuan J1P0, J2P0, J2P1, dan J1P2. terhadap bobot buah per tanaman. Hasil uji lanjut disajikan pada Tabel 2.

Tabel 2. Rata-rata Bobot Buah (kg/tanaman)

\begin{tabular}{|c|c|c|c|c|c|}
\hline \multirow[b]{2}{*}{ Jarak tanam } & \multicolumn{3}{|c|}{ Pemangkasan } & \multirow[b]{2}{*}{ Rata-rata } & \multirow[b]{2}{*}{ BNT 0,01 } \\
\hline & P0 & P1 & $\mathrm{P} 2$ & & \\
\hline $\mathrm{J} 1$ & 0,60 & 0,73 & 0,76 & $0,69^{\mathrm{a}}$ & \\
\hline $\begin{array}{c}70 \mathrm{~cm} \times 50 \mathrm{~cm} \\
\mathrm{~J} 2 \\
60 \mathrm{~cm} \times 50 \mathrm{~cm}\end{array}$ & 0,55 & 0,73 & 0,75 & $0,67^{\mathrm{b}}$ & 0,01 \\
\hline $\begin{array}{c}\mathrm{J} 3 \\
40 \mathrm{~cm} \times 50 \mathrm{~cm}\end{array}$ & 0,46 & 0,45 & 0,47 & $0,46^{\mathrm{c}}$ & \\
\hline Rata-rata & $0,53^{\mathrm{c}}$ & $0,63^{b}$ & $0,66^{\mathrm{a}}$ & & \\
\hline BNT 0,05 & 0,01 & & & & \\
\hline
\end{tabular}
BNT 0,05. 

Tabel 2 menunjukkan bahwa $0,63 \mathrm{~kg}$, dan perlakuan tanpa pemangkastanaman tomat yang menghasilkan an (P0) yaitu $0,53 \mathrm{~kg}$ (Tabel 2).

produksi tertinggi terdapat pada perlakuan jarak tanam $70 \mathrm{~cm} \times 50 \mathrm{~cm}(\mathrm{~J} 1)$ sebanyak Produksi per hektar $0,69 \mathrm{~kg}$ per tanaman, dan berbeda nyata Data hasil pengamatan produksi per dengan perlakuan jarak tanam $60 \mathrm{~cm} \times$ hektar tanaman tomat dan sidik ragamnya $50 \mathrm{~cm}(\mathrm{~J} 2)$ yaitu $0,67 \mathrm{~kg}$ dan perlakuan menunjukkan bahwa jarak tanam jarak tanam $40 \mathrm{~cm}$ x $50 \mathrm{~cm}$ (J3) yang berpengaruh sangat nyata, demikian pula menghasilkan 0,46 kg.

Pada perlakuan pemangkasan pemangkasan berpengaruh nyata tetapi interaksinya tidak berpengaruh nyata menyisakantiga cabang (P2) lebih tinggi terhadap produksi tomat per hektar. bobot buah yaitu $0,66 \mathrm{~kg}$, dan berbeda Perbedaan produksi pada setiap perlakuan nyata dengan perlakuan pemangkasan dapat dilihat pada Tabel 3. yang menyisakan dua cabang (P1) yaitu

Tabel 3. Rata-rata Produksi Per Hektar (ton/ha)

\begin{tabular}{|c|c|c|c|c|c|}
\hline \multirow{2}{*}{ Jarak tanam } & \multicolumn{3}{|c|}{ Pemangkasan } & \multirow[b]{2}{*}{ Rata-rata } & \multirow[b]{2}{*}{ BNT 0,01} \\
\hline & P0 & $\mathrm{P} 1$ & $\mathrm{P} 2$ & & \\
\hline $\begin{array}{c}\mathrm{J} 1 \\
70 \mathrm{~cm} \times 50 \mathrm{~cm}\end{array}$ & 17,04 & 22,57 & 21,61 & $20,40^{b}$ & \\
\hline $\begin{array}{c}\mathrm{J} 2 \\
60 \mathrm{~cm} \times 50 \mathrm{~cm}\end{array}$ & 18,22 & 24,11 & 24,99 & $22,44^{\mathrm{a}}$ & 1,65 \\
\hline $\begin{array}{c}\mathrm{J} 3 \\
40 \mathrm{~cm} \times 50 \mathrm{~cm}\end{array}$ & 22,67 & 22,50 & 23,33 & $22,83^{a}$ & \\
\hline $\begin{array}{l}\text { Rata-rata } \\
\text { BNT 0,05 }\end{array}$ & $\begin{array}{l}19,31^{\mathrm{b}} \\
1,65\end{array}$ & $23,06^{\mathrm{a}}$ & $23,31^{\mathrm{a}}$ & & \\
\hline
\end{tabular}

Keterangan : Angka yang diikuti oleh huruf yang berbeda menunjukkan berbeda nyata pada taraf uji BNT 0,05 

Tabel 3 menunjukkan bahwa jarak tanam $40 \mathrm{~cm} \times 50 \mathrm{~cm}(\mathrm{~J} 3)$ menghasilkan produksi tertinggi sebanyak 22,83 ton/ha, tidak berbeda nyata dengan perlakuan jarak tanam $60 \mathrm{~cm} \times 50 \mathrm{~cm}$ (J2) yaitu 22,44 ton/ha, namun berbeda nyata dengan perlakuan jarak tanam $70 \mathrm{~cm} \times 50 \mathrm{~cm}$ yaitu 20,40 ton/ha, sedangkan pemangkasan yang menyisakan tiga cabang (P2) nyata lebih tinggi yaitu 23,31 ton per hektar dan tidak berbeda nyata dengan pemangkasan yang menyisakan dua cabang (P1) yaitu 23,06 ton per hektar namun berbeda nyata dengan perlakuan tanpa pemangkasan (P0) yaitu 19,31 ton buah tomat per hektar.

\section{PEMBAHASAN}

\section{Pengaruh jarak tanam terhadap tanaman tomat}

Salah satu upaya untuk memperoleh produksi tomat yang optimal adalah dengan mengatur jarak tanam. Jarak tanam mempengaruhi pertumbuhan dan produksi tanaman tomat. Berdasarkan hasil Sidik ragam menunjukkan, jarak tanamtidak berpengaruh nyata terhadap, jumlah daun dan umur berbunga, sedangkan terhadap produksi buah berpengaruh nyata. Jarak tanam $70 \mathrm{~cm} \mathrm{x}$ $50 \mathrm{~cm}$ (J1) menghasilkan bobot buah tertinggi yaitu $0,66 \mathrm{~kg} / \mathrm{tanaman}$ dan berbeda nyata dengan jarak tanam $60 \mathrm{~cm} \mathrm{x}$ $50 \mathrm{~cm}$, dan $40 \mathrm{~cm}$ x $50 \mathrm{~cm}$. Semakin banyak tanaman per satuan luas maka semakin tinggi indeks luas daun sehingga persen cahaya yang diterima oleh bagian tanaman yang lebih rendah menjadi lebih sedikit akibat adanya penghalang cahaya oleh daun-daun diatasnya (Hanafi, 2005), sedangkan kalau dilihat dari produksi per hektar, maka penggunaan jarak tanam $40 \mathrm{~cm}$ x $50 \mathrm{~cm}$ menghasilkan produksi tertinggi 22,83 ton per hektar. Hal ini diduga bahwa tingginya produksi yang diperoleh pada jarak tanam $40 \mathrm{~cm}$ x $50 \mathrm{~cm}$ disebabkan populasi tanaman yang lebih banyak dibandingkan populasi tanaman pada jarak tanam $60 \mathrm{~cm} \times 50 \mathrm{~cm}$, dan $70 \mathrm{~cm}$ $\mathrm{x} 50 \mathrm{~cm}$. Hal tersebut sesuai dengan pernyataan Zaubin (1985) bahwa, dengan semakin rapatnya jarak tanam maka populasi akan semakin besar sehingga dapat meningkatkan hasil per satuan luas secara linier, tetapi apabila populasi tersebut terus ditingkatkan maka hasilnya akan menurun. Jarak tanam $40 \mathrm{~cm}$ x $50 \mathrm{~cm}$ (J3) memberikan pengaruh yang positif terhadap produksi tanaman tomat, karena jarak tanam $40 \mathrm{~cm} \times 50 \mathrm{~cm}$ masih termasuk kedalam jarak tanam yang renggang dan jumlah populasinya terbanyak dibanding- 
kan jarak tanam lainnya, sehingga man karena tanaman mudah terserang pertumbuhan dan perkembangan tanaman penyakit (Cahyono, 2003).

berjalan dengan baik dan produksinya meningkat. Selain itu pada jarak tanam $40 \mathrm{~cm} \times 50 \mathrm{~cm}$ diduga belum terjadi

\section{Pengaruh Pemangkasan Terhadap Tanaman Tomat}

kompetisi, sehingga tanaman dapat

Hasil sidik ragam menunjukkan tumbuh optimum dan lebih efisien dalam memanfaatkan sinar matahari, unsur hara, air dan udara $\left(\mathrm{CO}_{2}\right.$ dan $\left.\mathrm{O}_{2}\right)$. Hal ini sejalan dengan pendapat Dartius (1990) bahwa jarak tanam yang terlalu rapat menyebabkan tidak leluasanya pertumbuhan sehingga terjadi penindihan daun sesamanya disamping itu terjadi persaingan dalam memperoleh air, udara, unsur hara, dan intensitas cahaya matahari. Harjadi (1984) menyatakan bahwa jarak tanam dapat mempengaruhi populasi tanaman dan efisiensi penggunaan cahaya matahari serta kompetisi antara tanaman dalam memperoleh air maupun unsur hara. Pengaturan jarak tanam sangat mendukung pertumbuhan tanaman dan produksi.Jarak tanam juga sangat berpengaruh terhadap kondisi iklim mikro disekitar tanaman dan penerimaan sinar matahari.Jarak tanam yang rapat dapat menyebabkan kelembapan udara yang tinggi disekitar tanaman.Kondisi ini tidak menguntungkan untuk pertumbuhan tanabahwa perlakuan berbagai pemangkasan berpengaruh tidak nyata terhadap jumlah daun, dan umur berbunga, tetapi pemangkasan berpengaruh nyata terhadap bobot buah pertanaman dan produksi per hektar (Tabel 2 dan 3). Perlakuan pemangkasan yang menyisakan tiga cabang (P2) menghasilkan bobot buah $0,66 \mathrm{~kg}$ per tanaman dan produksi 23,31 ton per hektar. Hal ini disebabkan pemangkasan yang menyisakan tiga cabang menghasilkan bunga dan buah yang lebih banyak dibandingkan pemangkasan yang menyisakan dua cabang utama. Selain itu pemangkasan dapat mengurangi pertumbuhan vegetatif (daun/cabang) dan meningkatkan pertumbuhan generatif (buah) danmemperbanyak penerimaan cahaya matahari, menurunkan tingkat kelembaban disekitar tanaman, menghambat pertumbuhan yang tinggi agar mudah pemeliharaannya dan untuk menaikkan kualitas buah (Cahyono, 1996). 

berbagai Jarak Tanam dan Pemangkasan.

Pemangkasan dapat mendorong menjangkau seluruh bagian tanaman lebih cepat tumbuhnya tunas baru, yang sehingga efektif mengurangi kelembapan berpotensi untuk berbunga. Pemangkasan dan tanaman terhindar dari serangan hama selain dapat meningkatkan hasil bunga dan penyakit (Dewi, 2004; Sudaryani dan juga dapat memperbaiki kualitas bunga Sugiharti, 1989), sedangkan menurut dan penampilan atau figur tanaman menjadi lebih baik (Satsijah, 2008). Wochjar (1984) dalam Gernawi (1996), pada dasarnya pemangkasan bertujuan Tunas lateral merupakan subyek mengatur pertumbuhan vegetatif ke arah pengamatan korelasi oleh tunas apikal generatif. Dengan kata lain mengatur sehungga jika tunas apikal dipangkas maka hanya tunas lateral paling atas yang tumbuh dengan cepat sehingga tunas basal tetap terhambat. Penghambatan tunas lateral tergantung pada konsentrasi hormon auksin yang diberikan pada permukaan batang yang dipotong. Sebuah pemberian auksin eksogen pada tanaman yang dipotong akan merangsang pertumbuhan pucuk tanaman (Wilkins, 2004). Dominasi pucuk dapat dihilangkan melalui pemangkasan. Auksin dibentuk diujung batang dan ujung akar dari mana ia bergerak ke bagian lain dari tanaman, hasil akhir dari konsentrasi auksin berhubungan dengan pemangkasan (Anonim, 2010)

Pemangkasan bertujuan untuk meningkatkan produksi tanaman tomat, selain itu pemangkasan juga bertujuan memberi ruangan antara tanaman pada lahan agar penetrasi sinar matahari tanaman agar hanya menghasilkan cabang-cabang yang produktif. Apabila pemangkasan dilakukan maka fotosintat akan digunakan untuk memperbesar buah.

\section{Interaksi Antara Jarak Tanam dan Pemangkasan}

Hasil penelitian menunjukan bahwa terjadi interaksi antara jarak tanam dan pemangkasan terhadap umur berbunga tanaman tomat, namun tidak terdapat interaksi terhadap jumlah daun, produksi per tanaman dan per hektar. Hal tersebut menunjukan bahwa perbedaan respons tanaman tomat akibat pemangkasan tidak tergantung pada jarak tanam begitu pula perbedaan respon tanaman tomat akibat perbedaan jarak tanam tidak tergantung pada pemangkasan. Pada Tabel 1 menunjukkan bahwa jarak tanam $60 \mathrm{~cm} \mathrm{x}$ $50 \mathrm{~cm}$ dengan pemangkasan yang menyisakan tiga cabang mempercepat 


berbagai Jarak Tanam dan Pemangkasan.

pembungan tanaman tomat 19,67 hari dan interaksi antara jarak tanam $60 \mathrm{~cm} \times 50 \mathrm{~cm}$ dan pemangkasan yang menyisakan dua cabang primer menghasilkan tanaman tomat yang berbunga paling lambat yaitu 27 hari. Menurut Darjanto dan Satifah (1984), pembentukan bunga adalah peralihan dari fase vegetatif ke fase generatif. Peralihan tersebut sebagian ditentukan oleh faktor genetik dan sebagian lagi ditentukan oleh faktor lingkungan seperti suhu, cahaya kelembaban dan unsur hara. Dalam hal ini faktor genetik lebih dominan mempengaruhi umur berbunga dibandingkan dengan faktor lingkungan. Menurut Wiryanta (2004), suhu harian yang melebihi batas optimum pada tanaman dapat mempercepat terjadinya pembungaan. Kondisi ini disebabkan karena tanaman akan lebih cepat mengumpulkan satuan panas sehingga berdampak pada lebih cepatnya tanaman untuk membentuk bunga.

\section{KESIMPULAN}

1. Jarak tanam $40 \mathrm{~cm} \times 50 \mathrm{~cm}$ menghasilkan produksi per hektar yang lebih tinggi yaitu 22,83 ton per hektar.

2. Perlakuan pemangkasan dengan menyisakan 3 cabang utama mengha- silkan produksi tanaman terbaik sebesar 23,31 ton per hektar .

3. Jarak tanam $60 \mathrm{~cm} \times 50 \mathrm{~cm}$ dan pemangkasan yang menyisakan 3 cabang berpengaruh lebih terhadap umur berbunga $50 \%$ dengan umur berbunga 19,67 hari.

\section{DAFTAR PUSTAKA}

Anonim,2010.Http://Www.Tanindo.Com/ Abdi2/Hal0901.Htm. Diakses Pada Hari Rabu Tanggal 20 Juni 2012

Bernadus, T. \& W. Wahyu. 2002.

Bertanam Tomat. Agromedia Pustaka. Jakarta.

Cahyono, B., 2003. Kacang Buncis Teknik Budi Daya Dan Analisis Usaha Tani. Kanisius. Yogyakarta.Hal : 42.

Darjanto dan S. Satifah. 1984. Pengetahuan Dasar Biologi Bunga Dan Teknik Penyerbukan Silang. Gramedia. Jakarta

Dartius. 1990. Fisiologi Tumbuhan. USU Press. Medan.

Dewi, K. 2004. Pengaruh Jenis Pupuk Kandang Dan Jarak Tanam Terhadap Pertumbuhan Dan Produksi Jagung Manis (Zea Mays Saccharata Sturt). Skripsi. Departemen Budidaya Pertanian. Fakultas Pertanian. Institut Pertanian Bogor. Bogor. $42 \mathrm{Hal}$.

Fitriani.2012. Untung Berlipat Budidaya Tomat Di Berbagai Media Tanam. Pustaka Baru Press. Yogyakarta. 

berbagai Jarak Tanam dan Pemangkasan.

Gardner, F.P., R.B Pearce Dan R.L. Mitchell. 1991. Fisiologi Tanaman Budidaya. UI Press. Jakarta.

Gernawi, Y. 1996.Hasil Tanaman Tomat (Lycopersicum Esculentum Mil) Pada Berbagai Takaran Pupuk NPK Dan Pemangkasan. Laporan Penelitian. Balai PenelitianUniversitas Jambi. Jambi.

Hanafi,M.Arief. 2005. Pengaruh Kerapatan Tanam Terhadap Pertumbuhan Dan Hasil Tiga Kultivar Jagung (Zea mays L) Untuk Produksi Jagung Semi. Skripsi Fakultas Pertanian Universitas Brawijaya. Malang. Dalam Suryadi, Setyobudi, Dan Soelistyono, R., 2013. Kajian Intersepsi Cahaya Matahari Pada Kacang Tanah (Arachis Hypogaea L.) Diantara Tanaman Melinjo Menggunakan Jarak Tanam Berbeda. (Jurusan Budidaya Pertanian, Fakultas Pertanian, Universitas Brawijaya, Malang).

Harjadi, S.S. 1996. Pengantar Agronomi. Gramedia, Jakarta. Hal. 168-169.

Nuraini, Laili. 1993. Pengantar Ilmu Dan PengendalianGulma. Jakarta: Rajawali Press.

Primantoro. 2004. Hidroponik Buah Untuk Bisnis Dan Hobi. Penebar Swadaya. Jakarta.

Satsijah. 2008. Pengaruh Pemangkasan Dan Aplikasi Cycosel Terhadap Hasil Bunga

Sudaryani T, Sugiharti E . 1989. Budidaya

Dan Penyulingan Tanaman Nilam Jakarta (ID): Penebar Swadaya
Susiani, 2003. Pengaruh Dosis Pupuk NPK Dan Topping Terhadap Pertumbuhan Dan Hasil Tanaman Tomat (Lycopersicum Esculentum Mill) Jurnal Hortikultura 15(02):21-26

Sutomo, Hadi. 2005. Pedoman Bertanam Sayuran Dataran Rendah. UGM Press. Yogyakarta.

Wilkins, S. 2004. College Botany. University Of New York. New York

Wiryanta,W.T.B, 2004. Bertanam Tomat. Agromedia Pustaka, Jakarta.

Zaubin, M. 1985. Pengaruh Tumpangsari Jagung, Kacang Panjang,Dan Populasi Terhadap Produksi Bawang Putih (Allium Sativum L.). Laporan Penelitian. Fakultas Pertanian. Universitas Jember. Jember.74 Hal. 